$y D$

$$
\begin{aligned}
& \text { KEK P } 93-178 \\
& \text { SWg409 }
\end{aligned}
$$

KEK Preprint 93-178

December 1993

H

\title{
Radiation Harness of Lead Glasses TF1 and TF101
}

\author{
M. KOBAYASHI, Y. PROKOSHKIN, A. SINGOVSKY \\ and \\ K. TAKAMATSU
}

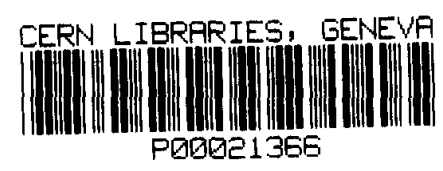

Submitted to Nucl. Instrum. Meth. 
National Laboratory for High Energy Physics, 1993

KEK Reports are available from:

Technical Information \& Library

National Laboratory for High Energy Physics

1-1 Oho, Tsukuba-shi

Ibaraki-ken, 305

JAPAN

$\begin{array}{lrl}\text { Phone: } & \text { 0298-64-1171 } & \\ \text { Telex: } & 3652-534 & \text { (Domestic) } \\ & (0) 3652-534 & \text { (International) } \\ \text { Fax: } & 0298-64-4604 & \\ \text { Cable: } & \text { KEK OHO } \\ \text { E-mail: } & \text { LIBRARY@JPNKEKVX (Bitnet Address) } \\ & \text { library@kekvax.kek.jp (Internet Address) }\end{array}$



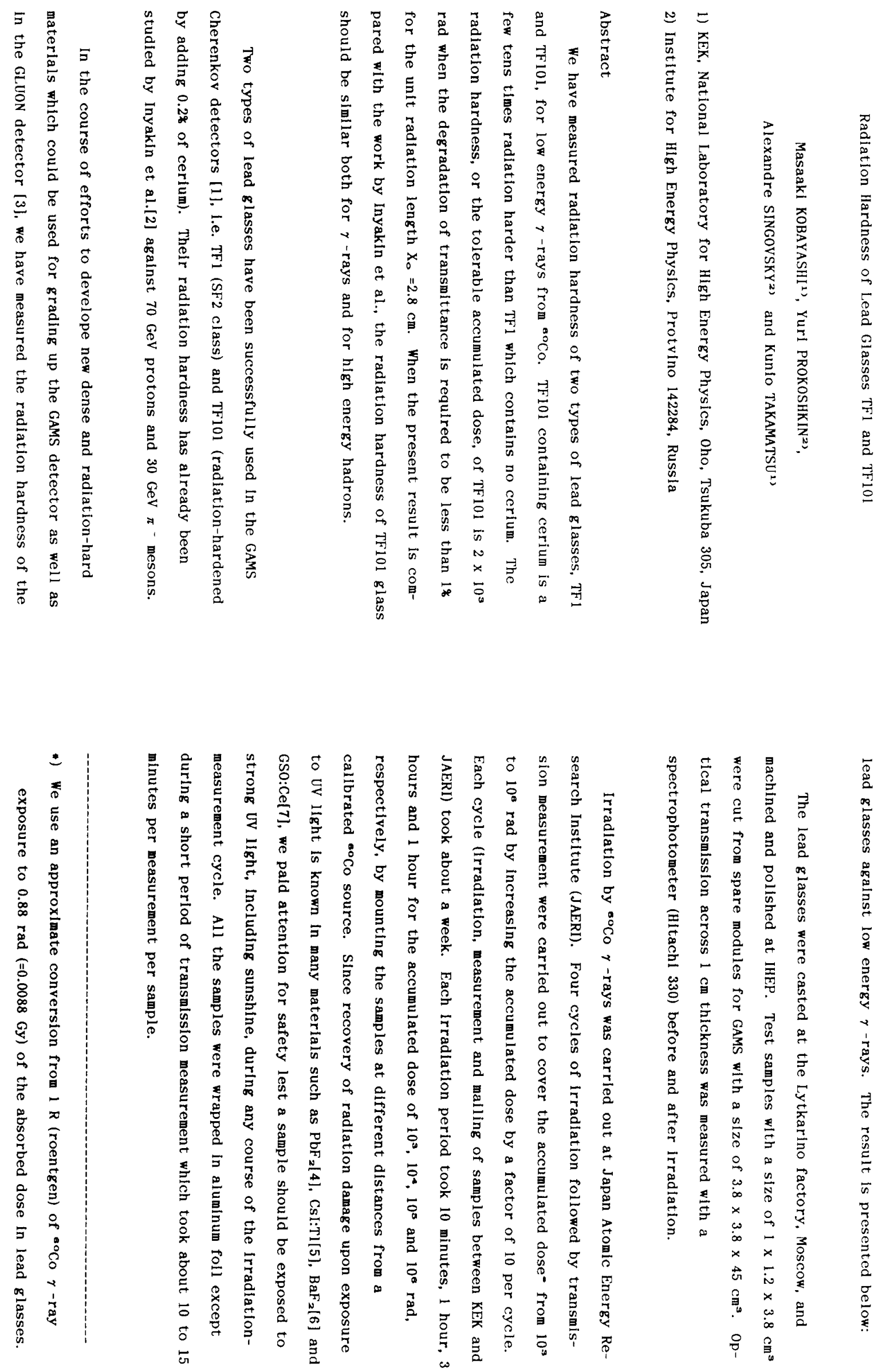

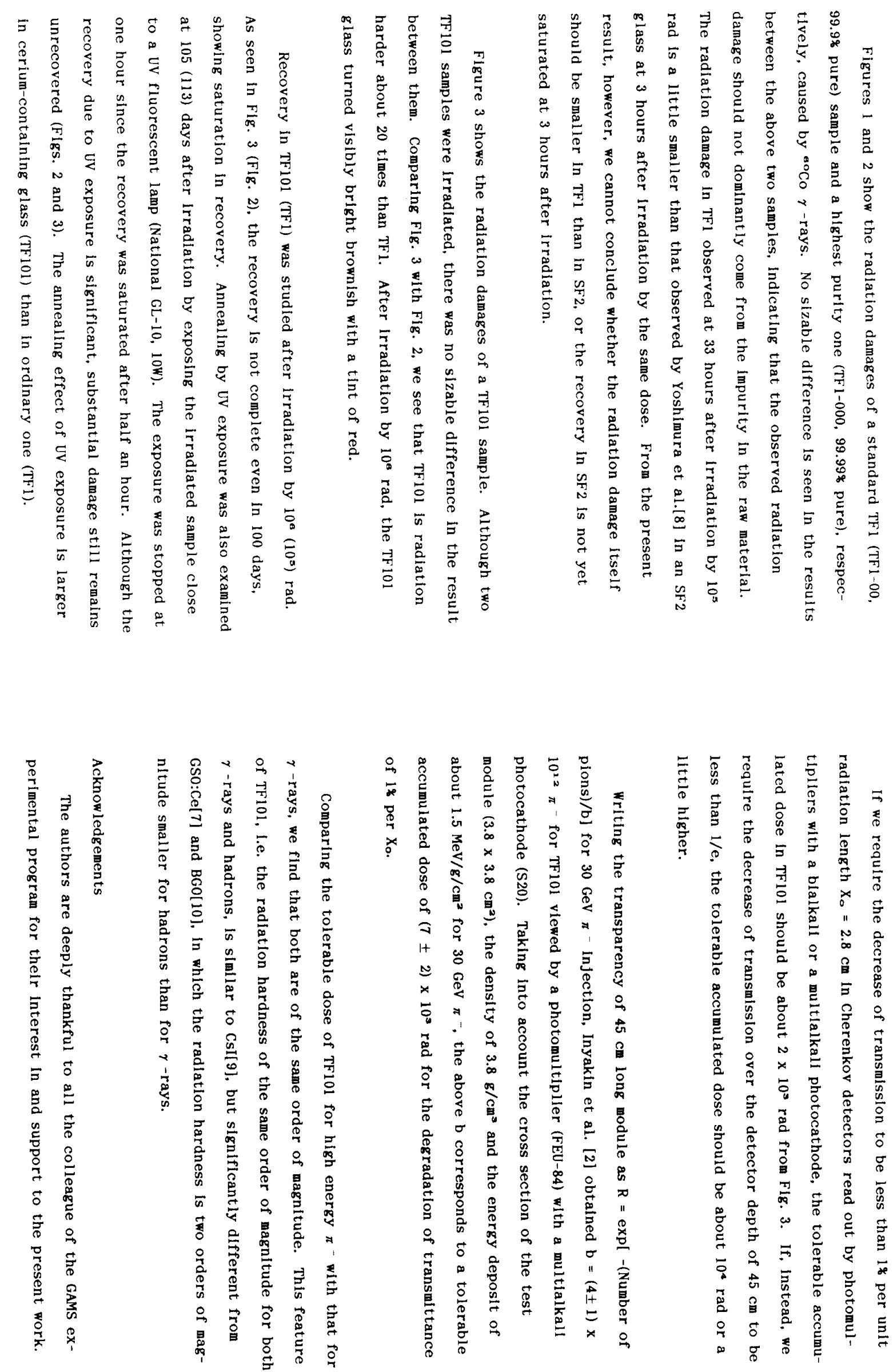

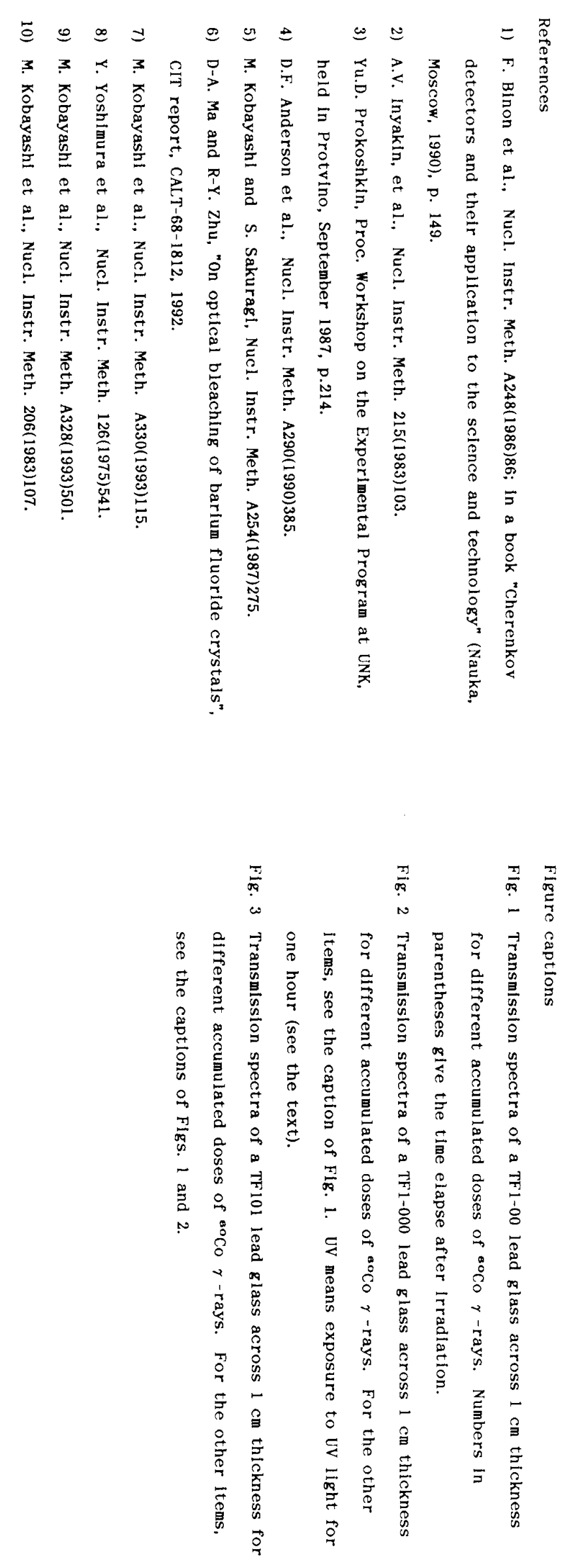

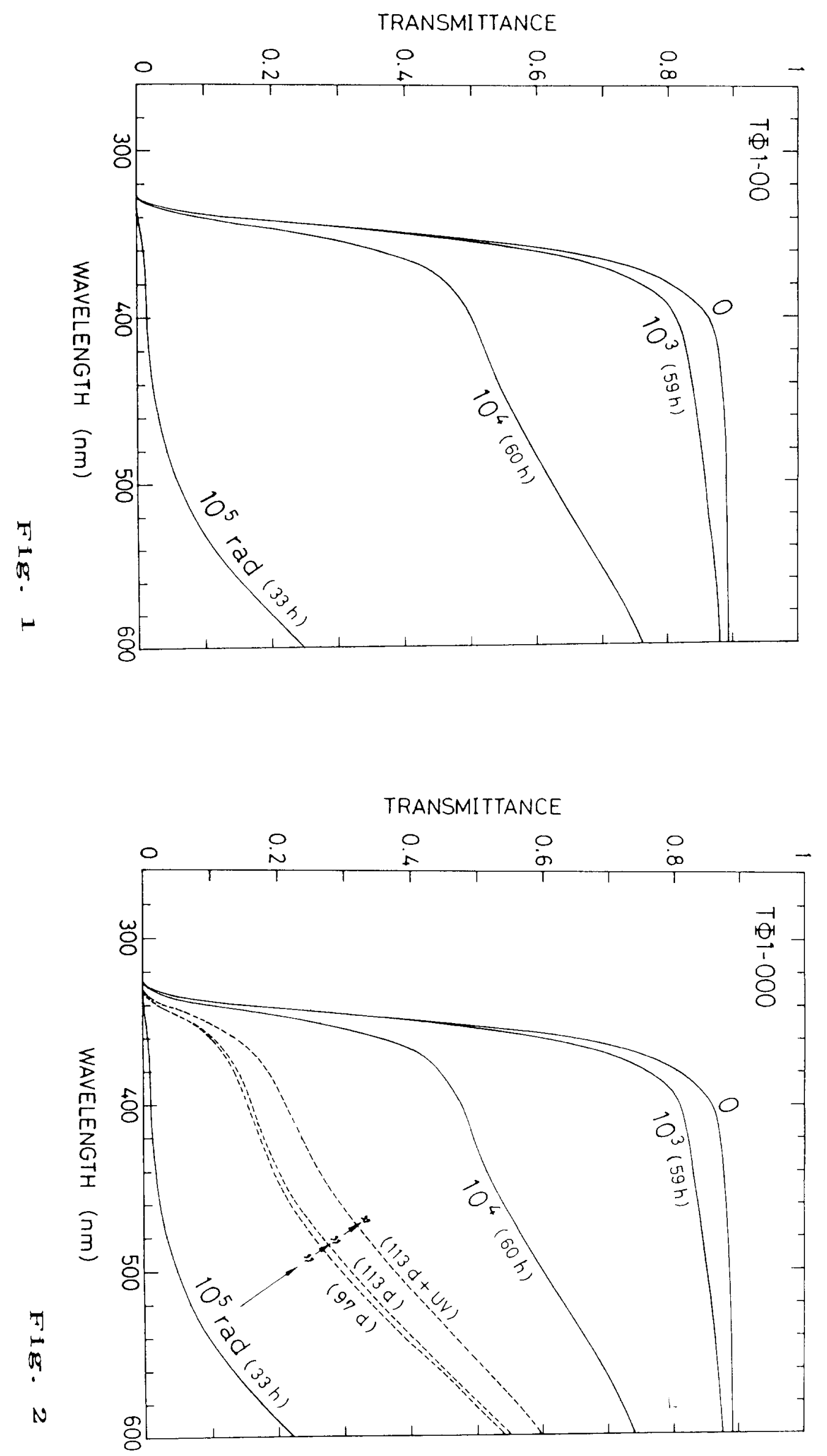


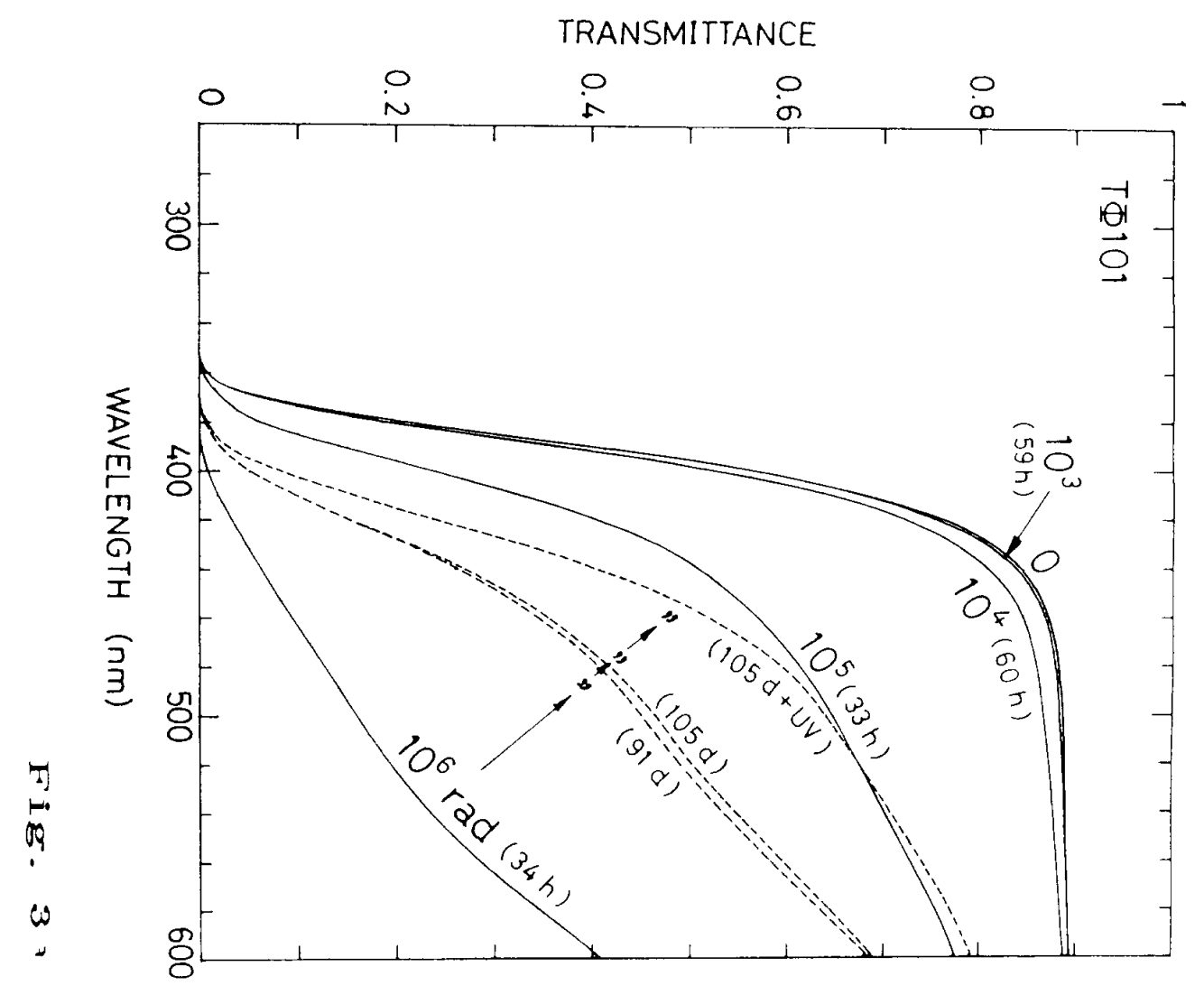


